\title{
The Lost Meteorites of Antarctica: Field campaigns and coordinated sample analysis approach to preliminary scientific study
}

\author{
KATHERINE H. JOY ${ }^{1}$, JANE L. MACARTHUR ${ }^{2}$, THOMAS \\ A. HARVEY ${ }^{2}$ AND RHIAN H. JONES ${ }^{2}$ \\ ${ }^{1}$ University of Manchester \\ ${ }^{2}$ The University of Manchester \\ Presenting Author: katherine.joy@manchester.ac.uk
}

Meteorites are the only natural source of material from beyond the Earth, providing invaluable evidence of how the Solar System formed and evolved. Over $66 \%$ of the total classified meteorites to date have been found in Antarctica [1,2], due to the ice dynamics and high katabatic winds producing highly concentrated localized Meteorite Stranding Zones (MSZs).

The Lost Meteorites of Antarctica project aims to explore new Antarctic MSZs to trial a method to collect sub-surface meteorites, testing the Evatt et al. [3] hypothesis that iron-rich meteorites are likely to lie buried a few $\mathrm{cm}$ below the surface [4,5]. Two field seasons in 2019 and 2020 visited the Outer Recovery icefields and Hutchinson icefields, both of which are south of the Shackleton Mountain Range / Recovery Glacier. We recovered a postulated 36 meteorites (season 1) and 85 meteorites (season 2), ranging from $\sim 2 \mathrm{~mm}$ to $20 \mathrm{~cm}$ in size. All samples were collected from the ice surface or were partially submerged in the ice. One sample was recovered from the top of Turner Nunatak. No englacial (sub-surface) meteorites were detected by the metal detector system we deployed [6].

For classification and preliminary scientific studies, we are undertaking a coordinated analysis of the recovered samples including: (i) photogrammetry to determine physical properties [7]; (ii) magnetic susceptibility and electrical conductivity measurements to determine metal presence and connectivity [7]; (iii) scanning electron microscope and electron microprobe analysis of polished blocks and thin sections for petrological characterisation; (iv) computed tomography to aid curation decision-making, (v) oxygen isotope analysis of selected samples. Meteorite classifications are currently in the process of being submitted to the Meteoritical Society nomenclature committee.

[1] Harvey R. (2003) Chemie der Erde -Geochemistry, 63, 93147. [2] https://www.lpi.usra.edu/meteor/ [3] Evatt G.W. et al. (2016) Nature Communications 7, doi:10.1038/ncomms10679 [4] Smedley, A.R. et al. (2020) Solar radiative transfer in The Cryosphere 14, 789-809 doi.org/10.5194/tc-14-789-2020 [5] https://ukantarcticmeteorites.wordpress.com/ [6] Wilson, J.W., et al. (2020) Antarctic Science, pp.1-12. DOI: https://doi.org/10.1017/S0954102019000531 [7] Harvey T. A. et al. (2021) 52nd Lunar and Planetary Science Conference. Abstract \#1897 